\title{
AVALIAÇÃO DE UMA PROPOSTA CONTEXTUALIZADA SOBRE O ENSINO DE POLARIMETRIA NOS CURSOS DE FARMÁCIA E ENGENHARIA DE ALIMENTOS, NA UNIVERSIDADE FEDERAL DO CEARÁ
}

\author{
Deyvison Henrique da Silva Rodrigues e Alcineia Conceição Oliveira* \\ Departamento de Química Analítica e Físico-Química, Universidade Federal do Ceará, Campus do Pici, 60455-900 \\ Fortaleza - CE, Brasil
}

Recebido em 15/3/08; aceito em 3/7/08; publicado na web em 15/12/08

\begin{abstract}
EVALUATION OF A CONTEXTUALIZED APPLICATION ABOUT POLARIMETRY FOR PHARMACY AND FOOD ENGINEERING COURSES AT UNIVERSITY FEDERAL OF CEARA. This work deals with an evaluation of an experimental application about polarimetry for pharmacy and food engineering courses. Foods obtained from the undergraduate students were used for demonstrating multidisciplinary concepts and these concepts were associated to the teaching of polarimetry. According to the results, the benefits of the contextualization are beyond the class and the undergraduating students became interested in control of quality of foods. From these results, it can be concluded that the experimental emphasis given is valid and creates motivation and interest for learning physico-chemistry, in comparison with the traditional methodology applied to teach polarimetry.
\end{abstract}

Keywords: physical chemistry; contextualization; graduate education.

\section{INTRODUÇÃO}

\section{A contextualização no ensino de química}

A abordagem contextualizada no ensino de química tem se mostrado eficiente para a compreensão dos conteúdos que envolvem o ensino-aprendizagem desta ciência. ${ }^{1-4}$ Para que tal binômio funcione é necessário que o docente interaja com seus alunos de modo a estimulálos e fazê-los compreender que os conceitos apreendidos em sala de aula serão úteis para o seu campo profissional, especialmente se o corpo discente é oriundo de áreas correlatas da química.

Especificamente, nota-se que a proposta pedagógica da universidade é conferir ao indivíduo a oportunidade de conhecer, possibilitando que ele se torne um membro da sociedade capaz de difundir o conhecimento e promover uma melhor qualidade de vida para todos. Portanto, o ensino superior voltado para a aprendizagem contextualizada configurase como uma motivação para estimular os estudantes graduandos a usar esse recurso no seu desenvolvimento profissional. ${ }^{5}$

Neste contexto, inserem-se as aulas práticas que, além de auxiliar na compreensão de um dado tema, possuem a propriedade de estimular iniciativas entre os alunos, no sentido de contribuir para a sua orientação profissional e o mercado de trabalho. Isto torna, por exemplo, as disciplinas de físico-química mais atrativas para os estudantes de graduação. 6,7

No presente trabalho, a estratégia de ensino será a utilização de materiais simples e de fácil obtenção (alimentos) como ferramenta para melhorar a compreensão dos conceitos sobre polarimetria, em uma disciplina de físico-química, na Universidade Federal do Ceará.

Nesse caso particular, nota-se que as disciplinas oferecidas para as áreas afins da química (farmácia, engenharia de alimentos), de forma geral, enfatizam o desenvolvimento de habilidades quantitativas. Por conseguinte, as dificuldades encontradas pelos estudantes de graduação culminam no pouco envolvimento destes com as disciplinas, refletindo-se nos elevados níveis de reprovação e/ou evasão semestrais.

*e-mail: alcineia@ufc.br
Assim, a integração teoria-prática e a contextualização do ensino, utilizando o cotidiano como ferramenta são propostos como forma de inter-relacionar os conteúdos específicos vistos em outras disciplinas com a físico-química. A percepção dos alunos também é mostrada neste trabalho.

\section{Motivação e justificativa para a escolha da proposta experimental}

O amido é um polissacarídeo (Figura 1a) de reserva encontrado na maioria dos vegetais, consistindo no carboidrato mais importante presente em amostras de alimentos como, por exemplo, a farinha. ${ }^{8}$

Este polissacarídeo contribui para a formação da estrutura, consistência e textura de massas e é fonte de açúcares para as leveduras. Além das propriedades citadas, o amido tem grande apli-

a)

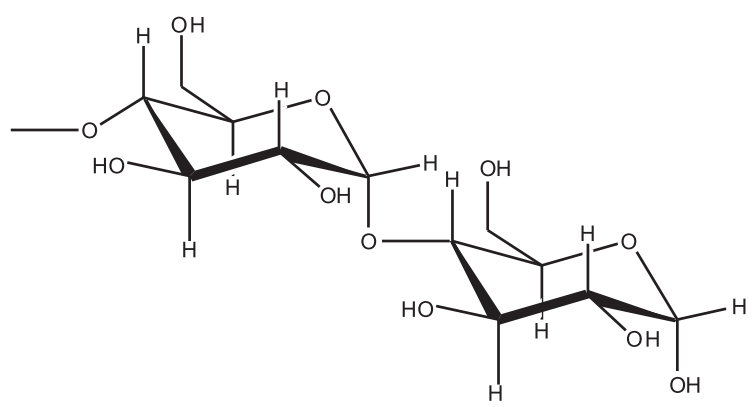

b)

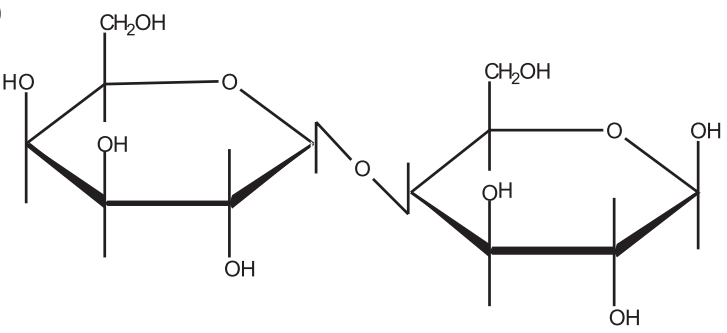

Figura 1. Estrutura do amido (a) e da lactose (b) 
cação na indústria de alimentos, principalmente como espessante e estabilizante..$^{9,10}$

A raiz da mandioca possui amido na sua composição e este vegetal desempenha um importante papel na dieta dos brasileiros, devido ao seu alto teor energético. ${ }^{10}$ Além disso, a mandioca se destaca como uma das principais culturas no Brasil, sendo que a maior parte da sua produção destina-se à fabricação de farinha de mandioca e o restante divide-se entre alimentação humana, animal e processamento para amido. ${ }^{11}$ A produção de farinha é uma atividade de importância social porque um grande contingente da população rural participa dessa produção. Nas regiões norte e nordeste do Brasil, a mandioca é a principal fonte de carboidrato para uma significativa parcela da população de menor poder econômico.

Sob outra perspectiva, a lactose é um carboidrato de origem animal que tem um papel relevante na alimentação humana, sendo um dissacarídeo abundante no leite e seus derivados. A lactose ou galactose $\beta-1,4$ glucose é um dissacarídeo formado por uma unidade de glicose e outra de galactose (Figura 1b). Entre as particularidades físico-químicas, apresenta baixa solubilidade quando comparado a outros açúcares comuns na alimentação. ${ }^{12}$ Entre outras particularidades, o leite humano contém de 6 a $8 \%$ de lactose, enquanto que o leite de vaca apresenta cerca de $4-6 \%$ deste carboidrato. ${ }^{13}$

Neste contexto, a determinação do teor de amido e lactose em amostras de alimentos pode ser uma ferramenta poderosa para ilustrar conceitos multidisciplinares. Especificamente, em físico-química, a técnica polarimétrica é utilizada para a determinação de substâncias oticamente ativas, em solução, através da lei de Biot. ${ }^{14}$ Ambas as substâncias são dextrógiras. Assim, tanto o amido como a lactose podem ser determinados com o objetivo de se realizar o controle de qualidade em amostras de alimentos, por via direta, através da determinação dos teores dos referidos constituintes.

Desta forma, o presente trabalho teve por objetivo utilizar a técnica de polarimetria para demonstrar a aplicação desta técnica em análise de alimentos, constituindo-se uma ferramenta didática para o ensino contextualizado de físico-química, nos cursos de farmácia e engenharia de alimentos.

Especificamente, a proposta experimental consistiu em desenvolver os seguintes tópicos: determinar o teor de amido em amostras de alimentos, tais como amido de milho (maisena), batata inglesa e farinha de mandioca; estimar o teor de lactose em amostras de creme de leite e de leite magro; associar estes resultados àqueles obtidos por técnicas como viscosimetria e picnometria; determinar o teor de cinzas nas amostras de farinha de mandioca e amido de milho; avaliar a percepção dos estudantes de graduação quanto à nova proposta experimental.

\section{METODOLOGIA}

O trabalho constituiu-se de três etapas: levantamento prévio das dificuldades encontradas pelos alunos dos cursos das áreas correlatas da química; desenvolvimento/adaptação da metodologia experimental; percepção do corpo discente sobre a proposta apresentada.

Assim, foi possível correlacionar as informações obtidas e elaborar propostas para a melhoria da metodologia.

\section{Levantamento prévio}

Os alunos dos cursos de farmácia e engenharia de alimentos regularmente matriculados, respectivamente, nas disciplinas FísicoQuímica Aplicada à Farmácia e Fundamentos de Físico-Química, oferecidas semestralmente pelo Departamento de Química Analítica e Físico-Química da UFC, foram consultados por um dos autores deste artigo. Essas disciplinas, cujas cargas horárias são de 6 h/aulas sema- nais ( 4 h teóricas, $2 \mathrm{~h}$ práticas) são oferecidas no $2^{\circ}$ semestre do curso de farmácia e no $3^{\circ}$ semestre do curso de engenharia de alimentos. No $1^{\circ}$ semestre de 2007, havia 50 alunos dos referidos cursos inscritos nas disciplinas, sendo que 42 participaram efetivamente da consulta, cujo caráter era opcional. O questionário aplicado pelo monitor da disciplina é mostrado no Quadro 1:

Quadro 1. Questionário aplicado aos graduandos, antes da aplicação da proposta experimental

\section{QUESTIONÁRIO}

1. Qual o seu interesse na disciplina?

2. Qual o nível de dificuldade em físico-química?

3. Você consegue associar as aulas teóricas e práticas com os conceitos vistos nas disciplinas prévias de química geral e inorgânica, química orgânica e química analítica com a disciplina de físico-química estudada?

4. Você conseguiria associar os temas vistos na disciplina com os aspectos que serão utilizados na sua futura profissão?

5. Ao que você atribui a dificuldade na disciplina?

6. Qual, dentre as técnicas estudadas, picnometria, viscosimetria, refratometria, polarimetria, você encontrou mais dificuldade de compreensão? Por quê?

7. O que você aprendeu na disciplina? (pergunta aplicada no final do semestre)

\section{Metodologia experimental}

Diante das respostas do questionário, no $2^{\circ}$ semestre de 2007, o monitor da disciplina (estudante de farmácia) desenvolveu/aperfeiçoou a metodologia experimental para o estudo da polarimetria. Solicitou-se que os alunos, previamente, trouxessem amostras de alimentos, como amido de milho (maisena), batata inglesa e farinha de mandioca, além de leite e creme de leite para posterior aplicação da técnica de polarimetria.

As amostras de amido de milho (maisena), batata inglesa e farinha de mandioca foram utilizadas para determinação do teor de amido, como se segue:

\section{Determinação do teor de amido}

O método utilizado foi aquele proposto pela Diretiva 1999/79/CE da comissão européia - Jornal Oficial das Comunidades Européias de 2/7/1999, com algumas modificações. ${ }^{15}$ Esse método compreende duas determinações descritas como se segue: a primeira determinação consistiu em obter o poder rotatório total $(\mathrm{P})$ da amostra que foi tratada com ácido clorídrico diluído, a quente. Em seguida, procedeu-se à filtração da solução que continha a farinha e mediu-se o desvio angular da solução em um polarímetro modelo WXG-4, marca Polax, munido de um tubo de 1,9 dm e lâmpada de sódio; a segunda, consistiu na determinação do poder rotatório das substâncias solúveis em etanol $40 \%\left(\mathrm{P}^{\prime}\right)$, na qual a amostra foi submetida à extração com etanol $40 \% \mathrm{v} / \mathrm{v}\left(\mathrm{d}=0,948 \mathrm{~g} \mathrm{~mL}^{-1}\right.$, a $\left.20^{\circ} \mathrm{C}\right)$. Após a acidificação do filtrado com ácido clorídrico e a posterior homogeneização, mediuse o desvio angular, similarmente à proposta descrita na primeira determinação. A diferença entre os valores de $\mathrm{P}$ e $\mathrm{P}^{\prime}$ obtidos nas duas medições foi multiplicada por um fator conhecido, e esse resultado é dividido pelo poder rotatório específico do amido puro, de acordo com a Equação 1: ${ }^{15}$

Percentual de amido $=\frac{2000\left(\mathrm{P}-\mathrm{P}^{\prime}\right)}{[\alpha]_{\mathrm{D}}^{20}}$ 
em que: $\mathrm{P}=$ desvio angular total, em graus angulares; $\mathrm{P}^{\prime}=$ desvio angular das substâncias solúveis em etanol, em graus angulares; $[\alpha]_{\mathrm{D}}^{20}=$ rotação específica do amido puro; valores utilizados: $+185,4^{\circ}$ (batata inglesa) $+185,6^{\circ}$ (amido de milho), de acordo com a literatura. ${ }^{15}$ Para a determinação de amido na amostra de farinha adotou-se $+185,0^{\circ}$ como o valor do poder rotatório específico, dada a escassez de dados quanto a este item na literatura.

Previamente à determinação do desvio angular total, pesou-se aproximadamente 2,5 g das amostras de amido de milho, batata inglesa ou farinha de mandioca. Transferiram-se as amostras separadamente para um erlenmeyer de $100 \mathrm{~mL}$; em seguida, adicionou-se $25 \mathrm{~mL}$ de ácido clorídrico $(1,128 \% \mathrm{~m} / \mathrm{v})$, sob agitação continua, por $10 \mathrm{~min}$. Adicionou-se à mistura prévia, mais $25 \mathrm{~mL}$ do referido ácido e o sistema foi aquecido a $60{ }^{\circ} \mathrm{C}$, durante $15 \mathrm{~min}$. Posteriormente, arrefeceram-se os recipientes contendo as soluções a temperatura ambiente e adicionou-se $5 \mathrm{~mL}$ de solução de Carrez I (21,9 g de acetato de zinco e $3 \mathrm{~g}$ de ácido acético glacial em solução aquosa). Adicionou-se, em seguida, $5 \mathrm{~mL}$ de solução de Carrez II (10,6 g de ferrocianeto de potássio dissolvido em $50 \mathrm{~mL}$ de água). $\mathrm{O}$ volume do recipiente contendo as amostras de alimento foi completado até $100 \mathrm{~mL}$ com água destilada, mantendo cada sistema sob agitação. Por fim, homogeneizou-se e filtrou-se cada solução.

Para a determinação do desvio angular das substâncias solúveis em etanol 40\% v/v, pesou-se aproximadamente 5,0 $\mathrm{g}$ de amido de milho, batata inglesa ou de farinha de mandioca. Transferiram-se as amostras separadamente para um erlenmeyer de $100 \mathrm{~mL}$, adicionando-se $80 \mathrm{~mL}$ de etanol $40 \% \mathrm{v} / \mathrm{v}$. As amostras foram deixadas em repouso durante $1 \mathrm{~h}$, agitando-se periodicamente nesse ínterim, seis vezes, para que se tornassem homogêneas com a presença de etanol. Completou-se o volume de cada balão com água destilada e filtraram-se as soluções que continham as amostras. Transferiu-se 50 $\mathrm{mL}$ do filtrado para um erlenmeyer e adicionou-se $2,1 \mathrm{~mL}$ de ácido clorídrico $\left(25 \% \mathrm{~m} / \mathrm{m}, \mathrm{d}=1,126 \mathrm{~g} \mathrm{~mL}^{-1}\right)$, agitando-se vigorosamente. Submeteu-se cada erlenmeyer ao tratamento térmico em um sistema de refluxo adaptado, durante $15 \mathrm{~min}$. Transferiu-se o conteúdo de cada erlenmeyer para balões volumétricos de $100 \mathrm{~mL}$, arrefecendo-se as soluções a temperatura ambiente. Adicionou-se, simultaneamente, 5 mL de solução de Carrez I e 5 mL de solução de Carrez II. Completou-se o volume de cada balão com água destilada, homogeneizou-se e filtrou-se cada solução.

Em ambas as determinações, depois de filtradas, adicionaram-se às soluções cerca de $0,5 \mathrm{~g}$ de bissulfito de sódio e, posteriormente, acetato de chumbo, uma vez que as soluções de Carrez I e II não foram suficientes para clarificar as soluções, de modo satisfatório. A adição destes reagentes tem como objetivo clarificar as amostras para a posterior determinação polarimétrica.

\section{Determinação do teor de lactose}

A determinação do teor de lactose no leite magro e no creme de leite pode ser realizada através da polarimetria, após a precipitação das proteínas em meio ácido. Para realizá-lo, seguiu-se o procedimento experimental: ${ }^{13}$ pesaram-se alíquotas de $30 \mathrm{~mL}$ de creme de leite e $30 \mathrm{~mL}$ de leite magro, obtendo-se aproximadamente 28,0 $\mathrm{g}$ de cada amostra. Inicialmente, transferiram-se as amostras para dois erlenmeyers. Aqueceram-se as amostras, sob agitação a $55^{\circ} \mathrm{C}$, controlando rigorosamente a temperatura para evitar a hidrólise da lactose. Adicionou-se às amostras, gota a gota, $3 \mathrm{~mL}$ de ácido oxálico $5 \%(\mathrm{~m} / \mathrm{v})$ a fim de provocar a precipitação das proteínas do leite. Manteve-se a agitação por 10 min adicionais, até se observar uma boa coagulação das proteínas e separação da lactose presente no sobrenadante. Arrefeceu-se a amostra a temperatura ambiente e transferiu-se o sobrenadante (filtrado) de cada amostra para balões volumétricos de $100 \mathrm{~mL}$. Completou-se o volume dos balões com água destilada, posteriormente, homogeneizaram-se e filtraram-se as soluções. Adicionaram-se pequenas quantidades de acetato de chumbo, no intuito de clarificar as soluções.

\section{Determinação da viscosidade relativa das amostras de lactose}

Este experimento teve por objetivo a associação dos resultados obtidos por polarimetria com outras técnicas, como a picnometria e a viscosimetria, previamente estudadas nas aulas práticas.

As determinações das massas específicas e da viscosidade relativa das amostras de creme de leite e de leite magro foram efetuadas utilizando-se as técnicas de picnometria (através de um picnometro de $25 \mathrm{~mL}$ ) e o viscosímetro de Cannon-Fenske, à temperatura de $27,5^{\circ} \mathrm{C}$, de acordo com a metodologia proposta por Tavares et al. ${ }^{17}$

\section{Determinação do teor de cinzas}

As cinzas são resíduos inorgânicos remanescentes após a completa destruição da matriz orgânica do alimento. Sua determinação é bastante útil como indicativo para um parâmetro de qualidade analisado ou adulteração em alimentos. ${ }^{11} \mathrm{~A}$ determinação do teor de cinzas no amido de milho foi obtida utilizando-se um cadinho de porcelana previamente tarado; inicialmente, o cadinho contendo aproximadamente $1,0 \mathrm{~g}$ de amido de milho foi colocado em uma mufla a $150^{\circ} \mathrm{C}$ durante $10 \mathrm{~min}$, realizando-se, em seguida, a primeira pesagem. Elevou-se a temperatura da mufla até $540{ }^{\circ} \mathrm{C}$ e colocouse o cadinho de volta por mais $10 \mathrm{~min}$, realizando-se um total de 4 pesagens, até obter peso constante.

\section{Questionário de avaliação do experimento}

Após a realização da metodologia descrita, os alunos do $2^{\circ}$ semestre de 2007 responderam ao questionário apresentado no Quadro 2.

\section{RESULTADOS E DISCUSSÃO}

\section{Investigação preliminar sobre as dificuldades encontradas pelos estudantes na disciplina}

A estratégia utilizada nessa etapa do trabalho tinha o objetivo de conhecer a experiência anterior nas disciplinas da área da química e especificamente as impressões, por parte dos estudantes de graduação, acerca das disciplinas oferecidas (Físico-Química Aplicada à Farmácia e Fundamentos de Físico-Química). Ressalta-se também que o mesmo professor ministrava as aulas teóricas e práticas para as duas disciplinas. Os resultados obtidos encontram-se na Figura 2.

As disciplinas de físico-química ofertadas aos cursos de farmácia e engenharia de alimentos apresentavam-se pouco atrativas para os alunos das áreas correlatas da química, na opinião da maioria dos estudantes graduandos nela matriculados. Cerca de 54\% dos estudantes entrevistados visavam apenas serem aprovados na mesma (Figura 2a), sendo que o aprendizado ficava restrito ao segundo plano para $39 \%$ dos alunos. Isso é reflexo da dificuldade de aprendizado encontrada pelos estudantes, uma vez que o total de $70 \%$ afirmou que a disciplina é difícil ou muito difícil (Figura 2b). Adicionalmente, para $90 \%$ dos estudantes, não havia associação dos temas vistos nas aulas teóricas e práticas de físico-química, com as disciplinas prévias de química geral e inorgânica e química orgânica (Figura 2c).

Ainda, os pronunciamentos dos alunos revelaram que os conceitos vistos na disciplina não seriam aplicados para sua futura vida profissional, na opinião de $48 \%$ dos alunos (Figura 2d), essencialmente, por causa do aspecto quantitativo da disciplina. Essa impressão foi descrita como se segue:

"Só vejo cálculo em físico-química. Parece que nem neces- 
sitaria fazer outra disciplina das outras áreas da química, porque não as utilizo aqui. Às vezes quando há aulas práticas, não vejo utilidade da técnica para o meu curso...” (aluno do curso de farmácia).

Quadro 2. Questionário aplicado aos graduandos, após a aplicação da proposta experimental

\section{QUESTIONÁRIO 2}

1) Você entendeu o experimento?
( ) $\operatorname{sim}$
( ) não
( ) não sei

2) Na sua opinião ficou mais fácil entender a teoria e associá-la às técnicas envolvidas?
( ) $\operatorname{sim}$
( ) não
( ) não sei

3) É importante mostrar exemplos do dia a dia para compreender os assuntos mostrados na sala de aula?
( ) $\operatorname{sim}$
( ) não
( ) não sei

4) $\mathrm{O}$ experimento que foi feito no laboratório pode ser aplicado em sua vida profissional?
( ) $\operatorname{sim}$
( ) não
( ) não sei

5) Se os professores utilizassem exemplos do cotidiano ou exemplos que serão aplicados na sua vida profissional, isto facilitaria a compreensão dos temas em estudo?
( ) $\operatorname{sim}$
( ) não
( ) não sei

6) Dentre as disciplinas previamente estudadas (química orgânica, analítica e inorgânica) você conseguiria associá-las a físicoquímica?
( ) $\operatorname{sim}$
( ) não
( ) não sei

7) Foi mais fácil entender a técnica de polarimetria com a contextualização do tema?
( ) $\operatorname{sim}$
( ) não
( ) não sei

8) Se não houvesse aulas de laboratório, ficaria mais difícil entender as aulas?
( ) $\operatorname{sim}$
( ) não
( ) não sei

9) Como deve ser o relacionamento professor-aluno em uma disciplina?

( ) ótimo ( ) bom ( ) ruim ( ) péssimo
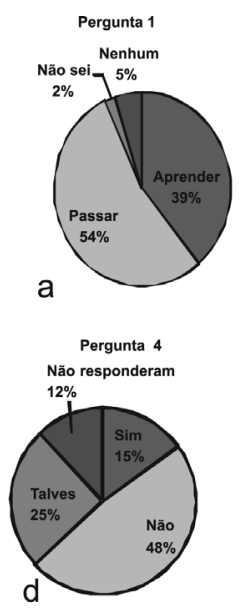
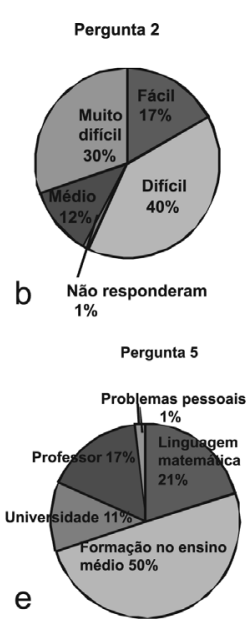

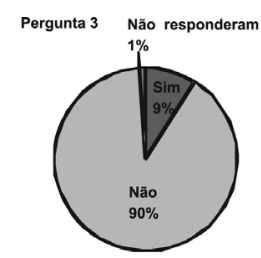

C

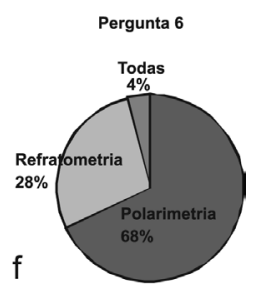

Figura 2. Respostas às perguntas do Questionário 1
"As aulas práticas são mais interessantes que as teóricas, mas o problema é que há falta de equipamento para todos realizarem os experimentos. Por este motivo, prefiro as aulas das outras áreas da química ou do meu próprio curso, porque estas me motivam..." (aluno do curso de engenharia de alimentos).

"Será necessária uma reformulação geral no curso, tanto teórico quanto prático, para que haja entendimento do conteúdo, de modo que não só se restrinja a quadro e laboratório..." (aluno do curso de farmácia).

"Sei que a matéria é importante para o meu curso. O problema é que o que aprendi nas disciplinas de orgânica, inorgânica ou nas do meu curso não são aplicadas diretamente na disciplina, e eu nem sei se vou utilizar isto..." (aluno do curso de engenharia de alimentos).

Infere-se ainda que a causa da dificuldade na disciplina fosse atribuída, por cerca de 50\% dos estudantes graduandos, ao despreparo devido à formação no ensino médio. Para $21 \%$ dos alunos, a linguagem essencialmente matemática dificulta a disciplina. A outra parcela dos estudantes identificou o professor (17\%), problemas pessoais (1\%) ou a própria Universidade $(11 \%)$ pela dificuldade encontrada ou a falta de êxito em físico-química (Figura 2e).

As concepções e atitudes com relação à disciplina, ao final do curso, mostraram que a técnica de polarimetria é complicada para $68 \%$ dos alunos (Figura 2f), enquanto que a técnica de refratometria foi a mais complicada para $28 \%$ dos alunos. Uma parcela menor dos estudantes (4\%) considerou difíceis todas as técnicas estudadas, viscosimetria, polarimetria, refratometria e picnometria. Adicionalmente, os estudantes relataram que não compreenderam o princípio teórico da técnica de polarimetria e/ou não irão aplicá-la na sua vida profissional; a aplicação de atividades em salas de aula e no laboratório deveria privilegiar a contextualização do tema para o bom entendimento do conteúdo transmitido pelo professor nas aulas, durante o desenvolvimento da disciplina.

Os depoimentos dos estudantes sobre a matéria, no final do curso, enfatizaram que para concluir a disciplina tiveram que recorrer à literatura, ao auxílio de colegas ou à monitoria, devido a sua dificuldade. Também relataram que o nível de assimilação dos conceitos estudados foi baixo e, como conseqüência, não aprenderam parte dos temas abordados. No entanto, para os entrevistados que não evadiram, o baixo rendimento acadêmico na Universidade era devido a sua formação no ensino médio ou ao caráter da disciplina, eminentemente quantitativa. Ressalta-se também que $17 \%$ dos alunos consideraram que o professor dificultou o entendimento da disciplina. Por consequiência, esta não acrescentaria na sua formação profissional.

Ressalta-se que os percentuais indicam a tendência de evasão na disciplina que naquele semestre atingiu $30 \%$, sendo que dos alunos remanescentes $43 \%$ foram aprovados.

Ainda, o número de estudantes entrevistados é extremamente restrito, quando comparado à enorme gama de estudantes inscritos na disciplina, ministrada no $1^{\circ}$ semestre de 2007. Deve-se ressaltar que nas referidas disciplinas, já existiam aulas contextualizadas sobre o experimento de polarimetria. Faz-se também alusão ao fato de que os alunos matriculados no $2^{\circ}$ e $3^{\circ}$ semestres, respectivamente, dos cursos de farmácia e engenharia de alimentos não cursaram grande parte das disciplinas das grades curriculares dos seus cursos.

Diante da análise preliminar realizada, observou-se que os relatos dos estudantes não mostram pontos de conexão entre a disciplina estudada e a aplicação desta, futuramente. A pesquisa também revelou que o nível de assimilação e concepções dos alunos, no que diz 
respeito aos tópicos enunciados, é abaixo do esperado, principalmente quanto à técnica de polarimetria.

Algumas outras observações ainda poderiam ser feitas quanto à avaliação prévia, no entanto, para ilustrar os benefícios da contextualização, tanto em sala de aula como em aulas de laboratório de físico-química, propomos um novo experimento relacionado à polarimetria, visto que esta é a técnica de mais difícil compreensão, segundo os estudantes.

Na tentativa de superar a disjunção entre as sub-áreas da química (orgânica, inorgânica, analítica) com a físico-química, bem como inter-relacionar e contextualizar as diferentes disciplinas, nessa etapa do trabalho, aplicou-se uma proposta de aula experimental, que visa integrar as sub-áreas da química, com aplicações nas áreas de farmácia e engenharia de alimentos.

No $2^{\circ}$ semestre de 2007, os alunos trouxeram alimentos como amido de milho (maisena), batata inglesa e farinha de mandioca, bem como leite e creme de leite. Previamente, o primeiro grupo de alimentos foi tratado de acordo com a descrição feita nos itens relacionados à determinação do amido na metodologia experimental, enquanto as amostras de leite foram tratadas de acordo com o descrito no item relacionado com a determinação deste carboidrato, na metodologia experimental.

\section{Dados experimentais obtidos pelos estudantes}

A aplicação mais comum da técnica de polarimetria é na determinação de concentração de substâncias opticamente ativas em solução, através da lei de Biot, conforme mencionado anteriormente. O desvio angular do plano de polarização da luz ao passar por uma solução depende do número de moléculas quirais que a luz encontra no seu trajeto. Esse ângulo depende do comprimento do tubo polarimétrico e da concentração da solução. A fim de se obter o referido desvio angular, os químicos calculam a grandeza denominada rotação específica, $[\alpha]$, de acordo com a Equação 2:

$[\alpha]_{D}^{20}=\frac{\alpha}{1 \times C}$

em que: $[\alpha]_{D}^{20}=$ rotação específica padrão da substância opticamente ativa a $20^{\circ} \mathrm{C}$, expressa em graus angulares; $\alpha=$ desvio angular observado, expresso em graus angulares; $c=$ concentração da solução, em g de substância opticamente ativa por $\mathrm{mL}$ de solução; $l=$ comprimento do tubo polarimétrico, em $\mathrm{dm}$.

A rotação específica também depende da temperatura e do comprimento de onda da luz. ${ }^{17} \mathrm{~A}$ Equação 2 foi utilizada para a determinação da concentração de lactose presente nas amostras.

Como mencionado anteriormente, o problema encontrado pelos alunos foi a dificuldade de compreensão da técnica de polarimetria, associada aos fundamentos teóricos que a cercam. Os alunos de ambos os cursos realizaram os experimentos descritos nos itens da metodologia deste trabalho, sendo que as amostras foram abertas pelo monitor da disciplina, devido ao número de horas de aula prática $(2 \mathrm{~h})$.

Em virtude da dificuldade de clarificação das amostras que continham amido, utilizou-se acetato de chumbo, uma vez que as soluções se apresentavam com turbidez acentuada, o que dificultou a leitura no polarímetro.

Previamente, o professor da disciplina descreveu, em uma aula, a fundamentação teórica da técnica, interagindo com os estudantes acerca de sua aplicabilidade. Em seguida, os estudantes realizaram a prática, com as amostras previamente abertas e preparadas pelo monitor. Os estudantes efetuaram somente a leitura das soluções no polarímetro.

Solicitou-se que os estudantes utilizassem outras técnicas estudadas anteriormente, como a viscosimetria e a picnometria, para correlacionar com o experimento de polarimetria. Após os experimentos, solicitou-se que os alunos confeccionassem relatórios sobre o tema proposto e discutissem os resultados obtidos, relacionando o tema carboidratos (funções orgânicas), controle de qualidade de alimentos, preparação de amostras para análise e a aplicação das técnicas estudadas para os cursos de farmácia e engenharia de alimentos.

Os experimentos foram realizados em réplica no semestre estudado e os resultados obtidos são mostrados na Tabela 1 .

Tabela 1. Massa, desvio angular total e desvio angular das substâncias solúveis em etanol de amostras de alimentos

\begin{tabular}{lccc}
\hline Amostra & Massa (g) & $\begin{array}{c}\text { Desvio angular } \\
\text { total } P \text { (graus) }\end{array}$ & $\begin{array}{c}\text { Desvio angular das } \\
\text { substâncias solúveis } \\
\text { em etanol } P^{\prime} \text { (graus) }\end{array}$ \\
\hline Amido de milho & 2,502 & 147,55 & 140,00 \\
$\begin{array}{l}\text { Batata inglesa } \\
\begin{array}{l}\text { Farinha de } \\
\text { mandioca }\end{array}\end{array}$ & 2,516 & 158,90 & 150,40 \\
\hline
\end{tabular}

De acordo com os valores dos desvios angulares ( $\mathrm{P}$ e $\left.\mathrm{P}^{\prime}\right)$ encontrados na Tabela 1 e os cálculos efetuados através da Equação 1, obtiveram-se os seguintes resultados: $81,8 \%$ de amido foi encontrado no amido de milho e $91,7 \%$ do mesmo carboidrato na batata inglesa, valores estes de acordo com o que se registrou na literatura para estes alimentos. ${ }^{15}$

No caso da amostra de farinha o teor de amido foi menor que $70 \%$. Os resultados obtidos foram repetidos pelo monitor da disciplina e os alunos optaram por trazer amostras de farinha de mandioca coletadas nos principais supermercados e feiras de Fortaleza-CE. Realizaram-se as análises físico-químicas de quatro amostras recolhidas no mercado municipal. Os dados revelaram que as quatro amostras de farinha de mandioca estudadas estão fora das especificações propostas pela legislação, ${ }^{9-11}$ uma vez que apresentaram um teor de amido inferior ao previsto pelas especificações $(<70 \%)$, além das amostras apresentarem sujidades.

No caso das amostras de creme de leite e leite magro, solicitou-se que os alunos utilizassem as técnicas de picnometria e viscosimetria previamente estudadas para determinar, respectivamente, as massas específicas e as viscosidades relativas das amostras (Tabela 2).

De acordo com os dados da Tabela 2, a massa específica das amostras aumenta com a quantidade de lactose e isto ocorre principalmente no creme de leite, comparado com o leite magro. Esta proporcionalidade foi também registrada quanto aos dados de tempo de escoamento e, por conseguinte, à viscosidade relativa. Ainda, a

Tabela 2. Massa específica, tempo de escoamento, viscosidade relativa e concentração de lactose em amostras de alimentos

\begin{tabular}{lcccc}
\hline Amostra & Massa específica ${ }^{\mathrm{a}}\left(\mathrm{g} \mathrm{mL}^{-1}\right)$ & Tempo de escoamento $^{\mathrm{b}}(\mathrm{s})$ & Viscosidade relativa $^{\mathrm{b}}$ & Concentração $^{\mathrm{c}}\left(\mathrm{g} \mathrm{mL}^{-1}\right)$ \\
\hline Água & $0,9963^{17}$ & 221,94 & 1 & - \\
Creme de leite & 0,9599 & 307,20 & 1,2499 & 0,020 \\
Leite magro & 0,8997 & 267,34 & 1,1499 & 0,015 \\
\hline
\end{tabular}

Dados obtidos por a picnometria, ${ }^{\mathrm{b}}$ viscosimetria e ${ }^{\mathrm{c}}$ polarimetria. $\mathrm{T}=27,5{ }^{\circ} \mathrm{C}$. 
análise polarimétrica das amostras de creme de leite e de leite magro apresentou leituras no polarímetro para a rotação observada $(\alpha)$ de $+2,1^{\circ}$ e $+1,6^{\circ}$, respectivamente. Tomando-se massa molar da lactose igual a $342 \mathrm{~g} \mathrm{~mol}^{-1}$, a rotação específica da lactose registrada na literatura, ${ }^{13}[\alpha]_{\mathrm{D}}^{20}$ igual a $+52,5^{\circ}$ e aplicando-se a Equação 2 , têm-se as concentrações de lactose de 0,020 e de $0,015 \mathrm{~g} \mathrm{~cm}^{-3}$, respectivamente, no creme de leite e no leite magro. Porém, os valores são próximos considerando a faixa de erro experimental da técnica.

Para a avaliação da pureza e da integridade do amido de milho, através da determinação do teor de cinzas, realizaram-se quatro pesagens até obter peso constante. Esses valores forneceram o teor de cinzas equivalente a $0,96 \%$. No caso da determinação do teor de cinzas da amostra de farinha de mandioca foram realizadas 6 pesagens. Esses valores forneceram o teor de cinzas equivalente a 1,62\%, não estando, portanto, em conformidade com a legislação vigente, que estabelece o máximo de $1,5 \%$ de cinzas para esse material. ${ }^{9}$ Os alunos concluíram após a análise que as amostras de farinha se encontravam fora das especificações e discutiram os possíveis riscos à saúde, em função das sujidades, como cabelo, grãos, insetos, dentre outras, apresentadas nas amostras.

\section{A avaliação da proposta}

As dificuldades encontradas pelos estudantes de graduação na área de química são constantemente relatadas em periódicos da área de educação. ${ }^{18-20}$ No entanto, é imprescindível conhecer os reais fatores que determinam tais dificuldades, a fim de saná-las ou diminuí-las. Dessa forma, os sujeitos do evento explicaram as razões que contribuem para o desinteresse na disciplina, dadas as respostas no questionário 1. Após a aplicação da proposta experimental, um segundo questionário (item metodologia, questionário de avaliação do experimento) foi aplicado para se verificar as impressões dos alunos, quanto à avaliação e aplicabilidade da proposta, cujos resultados são mostrados na Figura 3.

A Figura 3 mostra o percentual das respostas às perguntas (I-VII) direcionadas aos alunos. De acordo com a Figura, a proposta é válida, uma vez que mostrou boa aceitação, por cerca de $85 \%$ dos estudantes (Figura 3,I). Aproximadamente 10\% dos estudantes não entenderam o experimento e apenas $2 \%$ não souberam responder à pergunta formulada. Isso se deve ao fato de que o entendimento do conteúdo ministrado foi facilitado, culminando na avaliação positiva do experimento.

Ressalta-se também que, de acordo com os depoimentos dos estudantes, $91 \%$ deles opinaram que há um menor grau de dificuldade no entendimento da técnica, após a aplicação do experimento, sendo que para 9\% dos alunos (Figura 3,II) a dificuldade persistia, resultando na rejeição da proposta. Isto foi devido ao fato de que há pouco tempo de aula prática, o que dificultaria o cumprimento de todas as suas

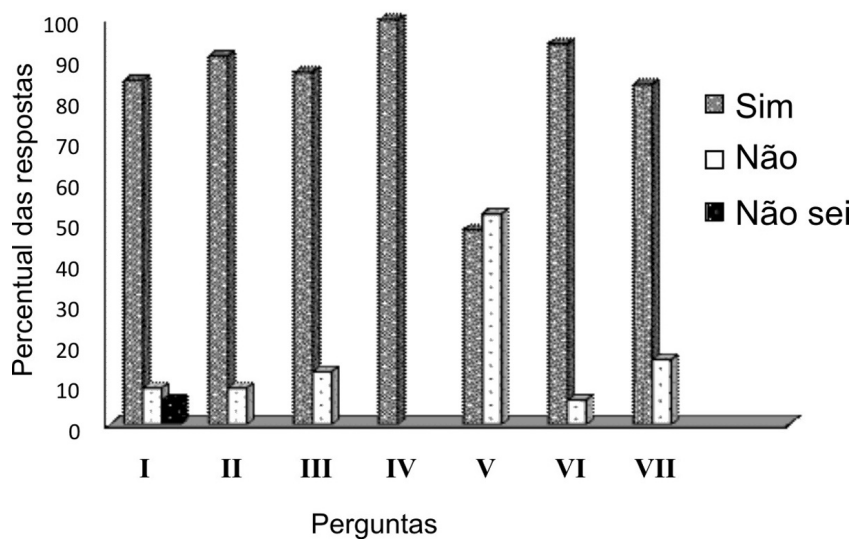

Figura 3. Percentual das respostas às perguntas (I - VII) respondidas pelos alunos etapas. Aplicando-se temas do cotidiano, voltados para sua formação profissional, há um maior grau de assimilação de conceitos relativos à disciplina, para $87 \%$ dos estudantes (Figura 3,III), enquanto que $13 \%$ ainda têm dificuldade de assimilação.

Para a totalidade dos estudantes graduandos entrevistados, o experimento feito em sala de aula terá utilidade na sua vida profissional (Figura 3,IV).

Associado a esse fator, deve-se ainda mencionar que $52 \%$ dos estudantes reconheceram que a abordagem dos tópicos contidos na disciplina não seria aplicada e, portanto, não acrescentaria na sua formação profissional, contra a opinião dos $42 \%$ dos entrevistados (Figura 3,V).

Além dos benefícios potenciais da proposta, as justificativas apresentadas pelos estudantes mostraram também que os assuntos focados em outras disciplinas da química devem ser abordados com mais profundidade e correlacionados com a disciplina ministrada, para 94\% dos alunos (Figura 3,VI); 6\% dos entrevistados não entendeu a técnica, mesmo com a abordagem contextualizada.

Para 84\% dos estudantes graduandos, as aulas de laboratórios são imprescindíveis para entendimento da teoria, contra $16 \%$ da opinião do corpo discente (Figura 3,VII). Embora o percentual não seja tão elevado, associando-os à ausência de ênfase na experimentação e aplicabilidade previamente observadas, esse resultado é um fator que mostra a necessidade de contextualização para que a físico-química não seja enfatizada como uma disciplina de "calculadora e quadro negro"; isto depende do professor que ministra a disciplina.

De acordo com a literatura, as experiências ilustrativas têm como característica as generalizações e/ou fatos ensinados anteriormente nas aulas teóricas, tradicionalmente nos cursos de ciências e tecnologia. Em contraposição, as experiências investigativas propiciam a elaboração e aquisição generalizada através da análise dos resultados experimentais. ${ }^{21}$ De acordo com tais considerações vimos, a partir da proposta aplicada, que ambas as experiências permitiram aos estudantes executar e desenvolver as capacidades intelectuais, propiciando uma aprendizagem significativa e respaldando seu crescimento profissional.

A relação professor-aluno foi questionada, com fins de verificar se tal binômio influenciaria no aprendizado. Para $80 \%$ da totalidade dos alunos entrevistados (Figura 4), o relacionamento deve ser bom/ ótimo, e isto influencia na aprendizagem. Em contraposição, cerca de $15 \%$ afirma que o relacionamento entre professor-aluno deve ser ruim. As razões para tal condição não tomam o foco do presente trabalho. Infere-se somente que uma boa relação docente-discente está associada à melhoria de aprendizado.

Os estudantes graduandos relataram em seus depoimentos que a aplicação da proposta leva em consideração conteúdos interdisciplinares, fatores sociais, como acessibilidade a alimentos de qualidade e fatores econômicos, como o custo das análises físico-químicas. Isso despertou o interesse pela disciplina.

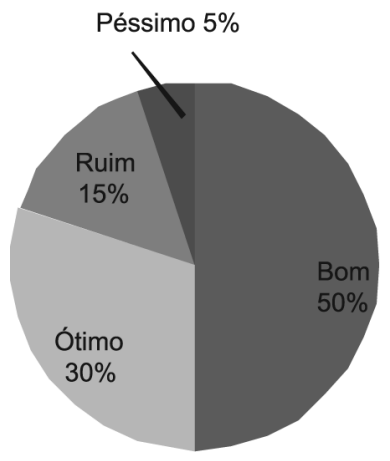

Figura 4. Avaliação do binômio professor-aluno 
É importante salientar que os dados da proposta mostram que os índices de reprovação diminuíram consideravelmente, ou seja, naquele semestre o desempenho dos alunos na disciplina melhorou progressivamente, o que reforça a constatação de que o direcionamento e o modo pelo qual o conteúdo é ministrado influenciam no aprendizado.

Adicionalmente, sabe-se que na formação acadêmica dos estudantes de cursos como farmácia e engenharia de alimentos deve-se contemplar a aplicação do conhecimento científico e tecnológico para a atuação dos profissionais de nível superior, em indústrias, laboratórios, empresas e, não raro, em centros de pesquisa. Deve-se, portanto, habilitar os estudantes universitários desses cursos, com ênfase na abrangência de técnicas, princípios físico-químicos ou propriedades químicas de materiais. Como consequiência, a formação acadêmica recebida pode se refletir no perfil do profissional e as habilidades requisitadas pelo mercado de trabalho podem ser reflexo do curso de graduação.

Em uma perspectiva geral, observa-se que os índices de evasão e repetência na disciplina de físico-química diminuíram com a aplicação da proposta. Isto está relacionado ao fato de que as causas que determinam a evasão parecem indicar que a parcela de culpa é devida à formação no ensino médio, do caráter quantitativo da disciplina e da própria Universidade, por não oferecer condições propícias ao aprendizado. O despreparo didático-pedagógico dos professores universitários, na opinião dos estudantes graduandos, influencia na aprendizagem. Destaca-se também que o perfil socioeconômico do aluno, o baixo desempenho acadêmico, bem como a infrequiência contribuem para os altos índices de repetência, nas referidas disciplinas.

O campo da físico-química é potencialmente quantitativo, desta forma, o desenvolvimento de habilidades qualitativas nas aulas é prejudicado e o uso freqüente da linguagem matemática conspira para o desinteresse dos estudantes nas disciplinas mencionadas. $\mathrm{Na}$ tentativa de atenuar tal situação ou pelo menos eliminar essas dificuldades constatadas, os professores usam muitas estratégias de ensino tanto em sala de aula como no laboratório para motivar o estudante; no entanto, esses recursos ainda estão longe de alcançar um resultado significativo, no que tange à compreensão dos conceitos de físicoquímica e envolvimento dos estudantes com as disciplinas.

Desta forma, uma medida para reduzir ou sanar os problemas apresentados seria enfocar as aulas contextualizadas nas referidas disciplinas, envolvendo conceitos multidisciplinares como uma ferramenta para desenvolver ações que minimizem substancialmente a ocorrência dos eventos citados. Propõe-se a oferta desta proposta, bem como se aceitam sugestões para o seu melhoramento para que o estudante graduando, oriundo de áreas afins da química, possa desenvolver dentre outras atividades, trabalhos relacionados à aplicação da físico-química para a sua área de atuação profissional. Tal proposta tem como objetivo principal ajudar a diminuir os índices de evasão e retenção nas disciplinas oferecidas, adotando metodologias inovadoras para a melhoria do binômio ensino-aprendizagem.

Dessa forma, a determinação de amido e lactose pode ser uma ferramenta para ilustrar conceitos como funções orgânicas, conceitos da química inorgânica, técnicas analíticas. Além disso, a polarimetria pode ser utilizada por via direta para determinação do teor dos constituintes, em amostras de alimentos. Para a melhoria da disciplina, acrescenta-se ainda que se deva adaptar os conteúdos das disciplinas de outros cursos à físico-química; incentivar o professor a buscar o aprimoramento do seu modo de ensinar; tornar as aulas de laboratório dinâmicas e interessantes; melhorar a relação professor-aluno dentre outras sugestões, oriundas da investigação proposta neste trabalho.

\section{CONCLUSÕES}

O presente trabalho inseriu-se na conjuntura de aplicação de um experimento para a contextualização do ensino de físico-química, nos cursos de farmácia e engenharia de alimentos. Utilizando-se amostras de alimentos, foi possível demonstrar conceitos multidisciplinares e associá-los ao ensino de polarimetria. Através desse estudo, demonstrou-se que se pode inserir uma proposta contextualizada, de boa receptividade por parte dos alunos, uma vez que a técnica aplicada foi direcionada ao controle de qualidade de alimentos. Conclui-se, portanto, que o experimento é válido e motiva os alunos para o estudo-aprendizagem de físico-química, juntamente com a metodologia tradicional utilizada no ensino de polarimetria.

\section{MATERIAL SUPLEMENTAR}

Está disponível em http://quimicanova.sbq.org.br, na forma de arquivo PDF, com acesso livre.

\section{AGRADECIMENTOS}

A F. Loureiro e aos Profs. J. R. P. Tavares e S. S. S. Borges pelo apoio no desenvolvimento deste trabalho e também pela leitura crítica deste manuscrito. Agradecemos também aos estudantes inscritos nas disciplinas de Físico-Química Aplicada à Farmácia-CF675 e Fundamentos de Físico-Química-CF684, no $1^{\circ}$ e $2^{\circ}$ semestres letivos de 2007 que participaram da pesquisa.

\section{REFERÊNCIAS}

1. Giordan, M.; Química Nova na Escola 1999, n.10, 43.

2. Rocha, F. R. P.; Martelli, P. B.; Reis, B. F.; Quim. Nova 2000, 23, 119.

3. Rinaldi, R.; Garcia, C.; Marciniuk, L.; Rossi, A. V.; Schuchardt, U.; Quim. Nova 2007, 30, 5.

4. Lima, J. F. L.; Pina, M. S. L.; Barbos, R. M. N.; Jofili, Z. M. S. A.; Química Nova na Escola 2000, n. 11, 26.

5. Farias, R. F.; Quim. Nova 2003, 26, 139.

6. da Costa Jr., J. S.; da Silva, F. C. M.; Moita Neto, J. M.; Quim. Nova 1999, $22,611$.

7. dos Santos, G. R.; Sá, L. P.; Queiroz, S. L.; Quim. Nova 2006, 26, 1121.

8. Solomons, T.W. G.; Química Orgânica, $7^{\mathrm{a}}$ ed., Editora LTC: Rio de Janeiro, 2002.

9. Chisté, R. C.; Cohen, K. O.; Mathias, E. A.; Ramos, A. G. A. J.; Ciênc. Tecnol. Aliment. 2006, 26, 861 .

10. http://www.engetecno.com.br/legislacao/cereais_farinha_mandioca.htm, acessada em Abril 2007.

11. Chisté, R. C.; Cohen, K. O.; Mathias, E. A.; Ramos, A. G. A. J.; Ciênc. Tecnol. Aliment. 2007, 27, 787.

12. Demiate, I. M.; Konkel, F. E.; Pedroso, R. A.; Ciênc. Tecnol. Aliment. 2001, 21, 108.

13. http://pt.wikipedia.org/wiki/Lactose, acessada em Março 2007.

14. Daniels, F.; Williams, J. W.; Bender, P.; Alberty, R. A.; Cornwell, C. D.; Experimental Physical Chemistry, ${ }^{\text {th }}$ ed., McGraw-Hill \& Kogakusha: New York, 1962.

15. http://eur-lex.europa.eu/LexUriServ/LexUriServ.do?uri=OJ:L:1999:20 9:0023:0027:PT, acessada em Março 2007.

16. http://www.dq.fct.unl.pt/cadeiras/aai/main/Trabalho\%20N4\%20Lactose. pdf., acessada em Abril 2007.

17. Tavares, J. R. P.; Manual de práticas de físico-química aplicada à farmácia, Universidade Federal do Ceará: Fortaleza, 2007.

18. Rosenthal, L. C.; J. Chem. Educ. 1991, 68, 494.

19. Tilstra, L.; J. Chem. Educ. 2001, 78, 762.

20. Queiroz, S. L.; Quim. Nova 2001, 24, 143.

21. Pessoa, O. F.; Ciência e Cultura 1999, 16, 364. 


\section{AVALIAÇÃO DE UMA PROPOSTA CONTEXTUALIZADA SOBRE O ENSINO DE POLARIMETRIA NOS CURSOS DE FARMÁCIA E ENGENHARIA DE ALIMENTOS, NA UNIVERSIDADE FEDERAL DO CEARÁ}

Deyvison Henrique da Silva Rodrigues e Alcineia Conceição Oliveira*

Departamento de Química Analítica e Físico-Química, Universidade Federal do Ceará, Campus do Pici, 60455-900 Fortaleza - CE, Brasil

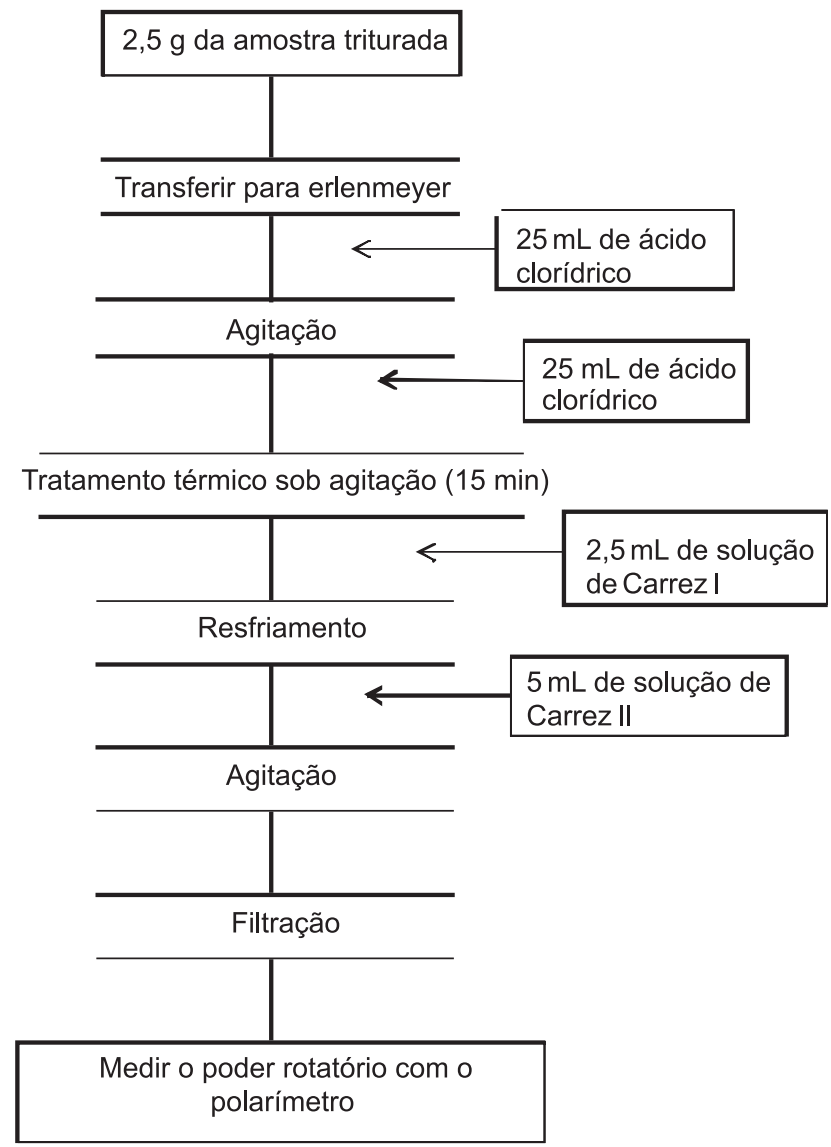

Figura 1S. Determinação do poder rotatório total $(P)$ para determinação de amido em amostras de farinha 


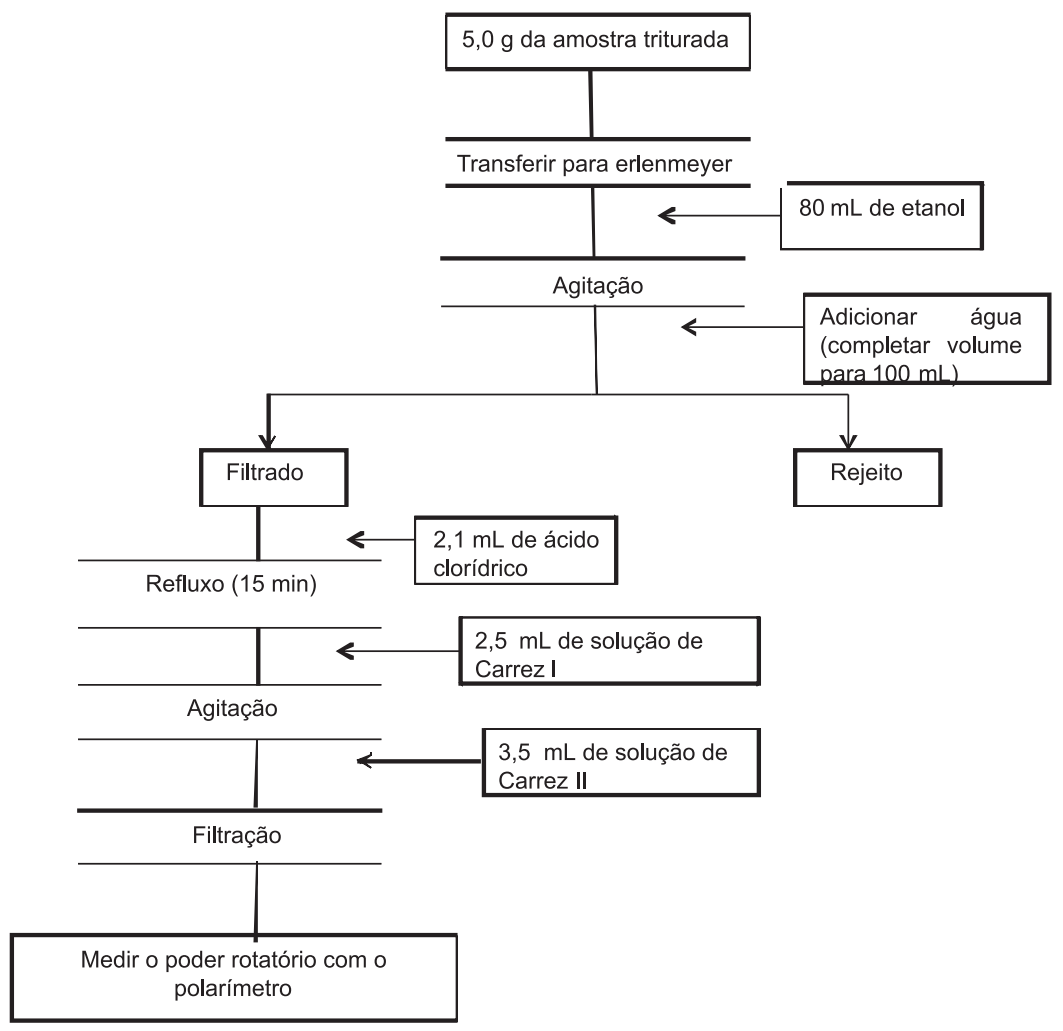

Figura 2S. Determinação do poder rotatório total para substâncias solúveis em etanol ( $\left.P^{\prime}\right)$, com o objetivo de se determinar o teor de amido em amostras de farinha

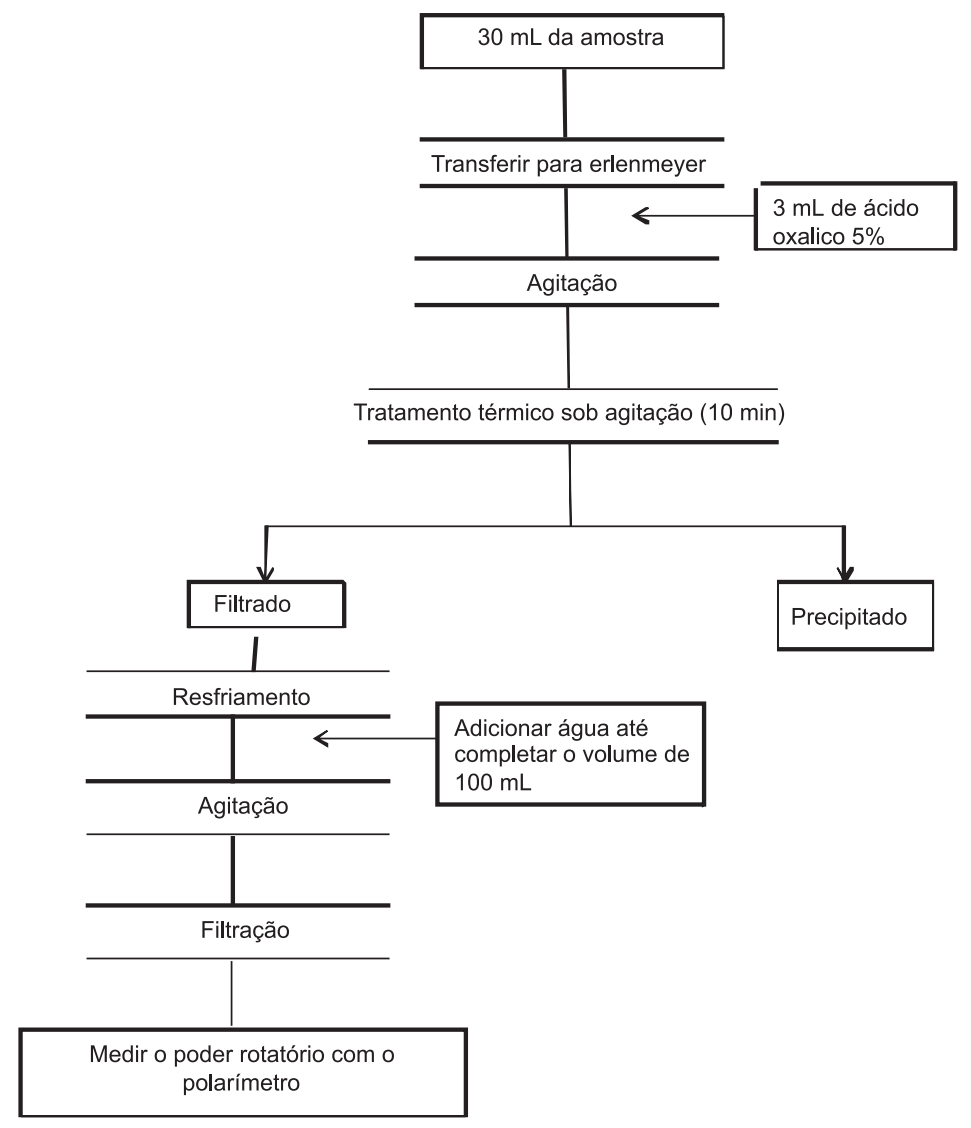

Figura 3S. Determinação do teor de lactose em amostras de leite e creme de leite 